\title{
Estrogen and estrogen receptor alpha promotes malignancy and osteoblastic tumorigenesis in prostate cancer
}

\author{
Sweta Mishra ${ }^{1}$, Qin Tai ${ }^{1,7}$, Xiang Gu${ }^{1}$, James Schmitz ${ }^{2}$, Ashley Poullard ${ }^{6}$, Roberto J. \\ Fajardo ${ }^{2}$, Devalingam Mahalingam ${ }^{3}$, Xiaodong Chen ${ }^{4}$, Xueqiong Zhu ${ }^{5}$, Lu-Zhe Sun ${ }^{1,3}$ \\ ${ }^{1}$ Department of Cellular and Structural Biology, University of Texas Health Science Center, San Antonio, Texas, USA \\ ${ }^{2}$ Department of Orthopedic Surgery, University of Texas Health Science Center, San Antonio, Texas, USA \\ ${ }^{3}$ Cancer Therapy and Research Center, University of Texas Health Science Center, San Antonio, Texas, USA \\ ${ }^{4}$ Dental School, University of Texas Health Science Center, San Antonio, Texas, USA \\ ${ }^{5}$ Department of Obstetrics and Gynecology, the Second Affiliated Hospital of Wenzhou Medical University, Wenzhou, China \\ ${ }^{6}$ Department of Medicine, Brown University, Providence, Rhode Island, USA \\ ${ }^{7}$ Department of Vascular Surgery, The Second Xiangya Hospital and Xiangya School of Medicine, Central South University, \\ Changsha, Hunan, China
}

Correspondence to: Lu-Zhe Sun, e-mail: SUNL@UTHSCSA.EDU

Keywords: prostate cancer, estrogen receptor, bone, osteoblastic, metastasis

Received: May 31, $2015 \quad$ Accepted: October 22, 2015

Published: October 31, 2015

\section{ABSTRACT}

The role of estrogen signaling in regulating prostate tumorigenesis is relatively underexplored. Although, an increasing body of evidence has linked estrogen receptor beta (ERß) to prostate cancer, the function of estrogen receptor alpha (ER $\alpha)$ in prostate cancer is not very well studied. We have discovered a novel role of ER $\alpha$ in the pathogenesis of prostate tumors. Here, we show that prostate cancer cells express $E R \alpha$ and estrogen induces oncogenic properties in prostate cancer cells through ER $\alpha$. Importantly, ER $\alpha$ knockdown in the human prostate cancer PacMetUT1 cells as well as pharmacological inhibition of ER $\alpha$ with ICI 182,780 inhibited osteoblastic lesion formation and lung metastasis in vivo. Co-culture of pre-osteoblasts with cancer cells showed a significant induction of osteogenic markers in the pre-osteoblasts, which was attenuated by knockdown of ER $\alpha$ in cancer cells suggesting that estrogen/ ER $\alpha$ signaling promotes crosstalk between cancer and osteoblastic progenitors to stimulate osteoblastic tumorigenesis. These results suggest that ER $\alpha$ expression in prostate cancer cells is essential for osteoblastic lesion formation and lung metastasis. Thus, inhibition of ER $\alpha$ signaling in prostate cancer cells may be a novel therapeutic strategy to inhibit the osteoblastic lesion development as well as lung metastasis in patients with advanced prostate cancer.

\section{INTRODUCTION}

Prostate cancer is the second leading cause of cancer-related death in the United States with an estimated 233,000 new cancer cases and 29,480 deaths reported in 2014 [1]. Given the widely recognized role of androgens in the development and progression of prostate cancer, androgen ablation therapy is the mainstay for the treatment of metastatic prostate cancer. However, most patients will eventually develop androgen-independent prostate cancer, highlighting an urgent need for the alternative treatment strategies. Although the growth and differentiation of prostate gland is primarily controlled by androgens, estrogens are also hormonal risk factors in the development of benign prostatic hyperplasia and prostate cancer $[2,3]$. Although estrogen therapy was historically used to reduce the androgen levels in men with advanced prostate cancer [4], more recent studies have also shown its involvement in prostate carcinogenesis. For example, estrogen can induce neoplastic epithelial morphology in both human and rat prostates and regulated prostate specific gene expression [5, 6]. Prolonged treatment 
of rodents with a high combined dose of androgen and estrogen induces stromal hypertrophy, epithelial dysplasia and enlargement of the prostate gland [7, 8]. Studies have suggested that anti-estrogens inhibit the development and progression of prostate cancer under experimental and clinical conditions $[9,10]$. Some of these anti-estrogen compounds are in clinical trials to study their efficacy in prostate cancer prevention $[11,12]$. The combination therapy of an estrogen receptor antagonist, tamoxifen with an anti-androgen bicalutamide, reduced gynecomastia and breast pain in prostate cancer patients receiving antiandrogen therapy in a multicenter trial [13]. Recently, a phase III clinical trial with a selective estrogen receptor modulator Toremifene, showed a significant reduction in new vertebral fractures in men with prostate cancer receiving androgen ablation therapy [11, 14]. Thus, understanding the oncogenic role of estrogen signaling in prostate carcinogenesis might provide a new therapeutic avenue for treating patients with advanced prostate cancer.

The presence of estrogen receptors (ER) in prostate suggests that estrogens may act directly in prostate epithelial cells [15]. The two ER subtypes, ER $\alpha$ and ERß, have different expression patterns with several studies presenting conflicting results in their expression as well as function during prostate carcinogenesis. ERß is regarded as the predominant subtype in majority of the epithelial cells, as well as in some stromal cells of the prostate. ERß is considered to be tumor suppressive in many cancers including the prostate [16-19]. ERß can cause antiproliferative effects as well as apoptosis in the castrationresistant basal epithelial cells in the prostates of aromatase knockout mice [20, 21]. Anti-estrogens can inhibit tumor growth through ERß-mediated regulation of the tumorsuppressing transcription factor KLF5 in prostate cancer cells [22]. However, a study by Zellweger et al. showed that ERß expression and AR phosphorylation correlated with poor clinical outcome in hormone-naïve prostate cancer and found increased ERß in castration-resistant phase of the disease [23]. The study by Leav et al. showed a reappearance of ERß expression in bone and lymph node metastasis, suggesting a causal link to the development of late stage disease [24]. A recent study showed that the ERß splice variant 2 (ERß2) had oncogenic properties and was involved in osteolytic bone metastasis in strong contrast to the tumor suppressing effects of the other isoform ERß1 [25]. Thus, differentiating the functions of splice variants for estrogen receptors will further elucidate our understanding of their roles in prostate cancer progression. While the role of ERß in prostate cancer is well studied, there are relatively few studies on the functional role of $\mathrm{ER} \alpha$ in prostate tumorigenesis. Estrogen was shown to mediate prostate cancer progression through ER $\alpha$ in a genetic knockout mouse model for both $\operatorname{ER} \alpha$ and $E R ß$ receptors [26]. While the prostates of wild type and ERß knockout mouse showed hyperplasia and PIN (prostatic intra-epithelial neoplasia) lesions when treated with testosterone and estrogen for four months, the prostates of ER $\alpha$ knockout animal did not develop these pathologies [26]. Furthermore, high ER $\alpha$ mRNA and protein levels were detected in hormone refractory and metastatic lesions with lymph node and bone metastatic samples [27]. However, the exact role of ER $\alpha$ in prostate tumorigenesis and formation of metastatic lesions has not been extensively investigated.

More than $80 \%$ of prostate cancer patients develop bone metastasis in the advanced stages of the disease [28]. The types of lesions that patients develop are predominantly osteoblastic or bone forming. The mechanism for the osteoblastic lesion development is poorly understood partly due to a lack of suitable model systems that recapitulates bone formation in the prostate cancer patients. The transgenic PTEN knockout mouse models have only a $27 \%$ bone metastasis incidence rate [29]. Prostate cancer cell lines such as PC-3, LNCaP, LuCaP, and LAPC-9 develop osteolytic or mixed lesions in immunocompromised mouse xenograft models [30]. We have shown previously that the human prostate cancer PacMetUT1 cell line induced extensive bone formation in vivo and could serve as a useful model for investigating the mechanism of osteoblastic lesion formation [31]. In this study, we have investigated the oncogenic roles of estrogen and ER $\alpha$ in various prostate cancer cell lines including PacMetUT1. Our results suggest that estrogeninduced osteoblastic bone formation and lung metastasis is mediated through ER $\alpha$. Thus, targeting ER $\alpha$ in prostate cancer patients with advanced metastatic disease might be a novel and efficient therapeutic strategy to reduce bone lesions and lung metastasis.

\section{RESULTS}

\section{Prostate cancer cells express ERo and are estrogen responsive}

The effects of estrogen are mediated by the intracellular estrogen receptors (ERs), which regulate transcription through binding to specific DNA sequences called EREs (estrogen response elements) in the promoter regions of their target genes. When we checked the $\operatorname{ER} \alpha$, ERß and AR status in different prostate cancer cells as well as in a benign prostatic hyperplasia cell line (BPH1), we detected ER $\alpha$ protein in some prostate cancer cells and ERß protein in all cell lines (Figure 1A and supplementary Figure 1A) even though ER $\alpha$ mRNA was detected in all the cells tested (Figure 1B). AR expression showed expected results with 22Rv1, LNCaP, and MDA$\mathrm{PCa}-2 \mathrm{~b}$ known to be AR positive, a moderate expression in PacMetUT1, and no expression in PC-3 and BPH-1 (Figure 1A and 1B). These cells were also responsive to estrogen as measured with the estrogen-responsive ERE-luciferase assay (Figure 1C). The responsiveness to 
estrogen was in part mediated by $\mathrm{ER} \alpha$ as $\mathrm{ER} \alpha$ agonist PPT also stimulated luciferase activity whereas ER $\alpha$ antagonist MPP reduced the basal luciferase activity driven by the ERE promoter (Figure 1D).

\section{Estrogen increases prostate cancer cell growth}

To check the effect of estrogen on cell growth, we treated PacMetUT1 with estrogen and two different ER antagonists, tamoxifen and ICI 182,780 (ICI) respectively. Estrogen significantly increased the cell growth after 5 days of treatment (Figure 2A and supplementary Figure 1B). Both tamoxifen and ICI decreased the cell growth, which was reversed by the addition of estrogen (Figure 2A) suggesting the functional involvement of ERs in the regulation of PacMetUT1 cell growth. Furthermore, using an ER $\alpha$ specific antagonist, MPP also reduced the cell growth that was regained by the addition of estrogen (Figure 2A). To determine the role of estrogen signaling in regulating the malignant properties of prostate cancer cells, we also examined its effect on anchorageindependent growth and cell migration. Estrogen significantly increased the number of spheres formed by PacMetUT1 cells in suspension culture (Figure 2B) and soft agar colonies (Figure 2C), which were antagonized by ICI. Estrogen also significantly increased the cell migration of both PacMetUT1 and 22Rv1 cells (Figure 2D) and in C4-2 cells (another bone metastatic cell line; Supplementary Figure 1C). Interestingly, unlike its effect on cell growth, the treatment with ICI itself had no effect on the basal level of cell migration (Figure 2D). This could be due to the shorter time treatment with ICI for the migration assay (16 hr of treatment) than for the growth assays ( 5 days on plastic, 2 days in suspension culture, or 7 days in soft agar) and/or insufficient basal level of estrogen in the system. Nevertheless, the treatment with ICI did abrogate the effect of exogenous estrogen-induced cell migration (Figure 2D). Consistently, treatment with ER $\alpha$ agonist PPT significantly increased the migration of PacMetUT1 whereas ER $\alpha$ antagonist MPP showed no

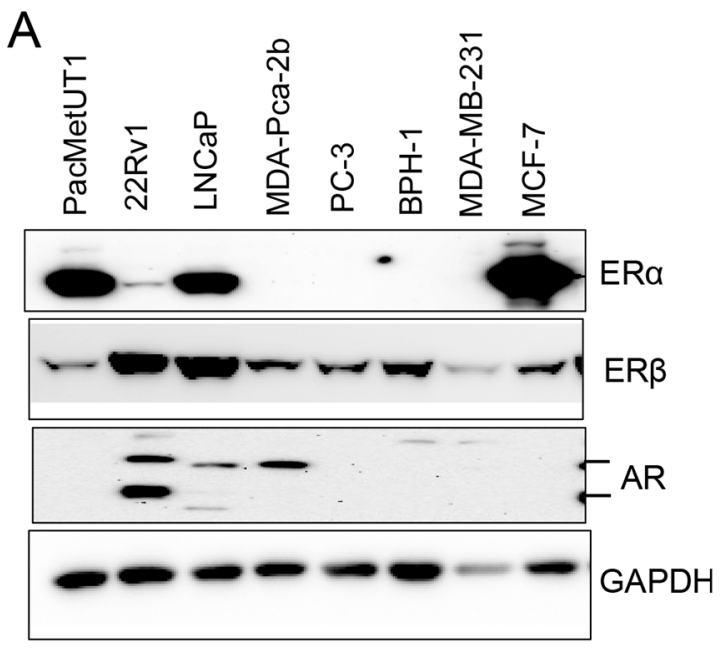

B
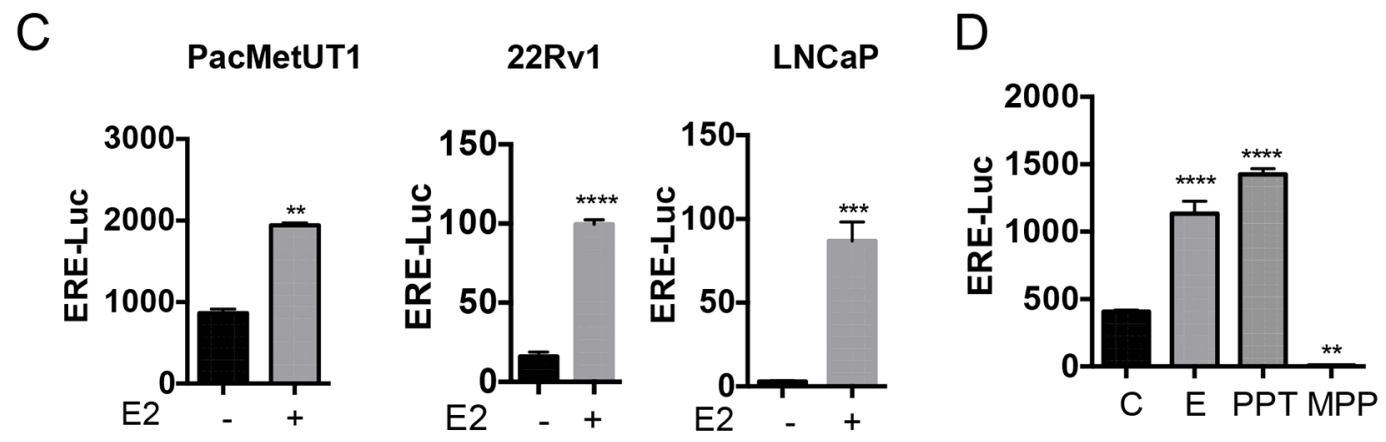

Figure 1: Prostate cancer cells are estrogen responsive. A and B. Cell lysates and cDNAs were used for ER $\alpha$, ERß and $A R$ expression analysis in different prostate cancer cell lines and the benign prostatic hyperplasia (BPH-1) cell line by Western blot and realtime RT-PCR respectively. The mRNA level of ER $\alpha$ and AR from real-time RT-PCR assays were normalized with the mRNA level of actin in each sample and presented as mean \pm sem from triplicate measurements. C. Estrogen responsiveness of prostate cancer cells was assessed using ERE-Luciferase reporter assay. ${ }^{*} P<0.01,{ }^{*} * *<0.001$ and $* * * * P<0.0001$ with two-tailed student's $t$-test. D. EREluciferase assay in PacMetUT1 cells with estrogen and ER $\alpha$ agonist PPT and antagonist MPP. ß-galactosidase normalized luciferase activity in both Panels $\mathrm{C}$ and $\mathrm{D}$ is presented as mean \pm sem from triplicate measurements. E2 and $\mathrm{E}$ have been used interchangeably. $* * P<0.01$ and $* * * * P<0.0001$ with one-way ANOVA analysis. 

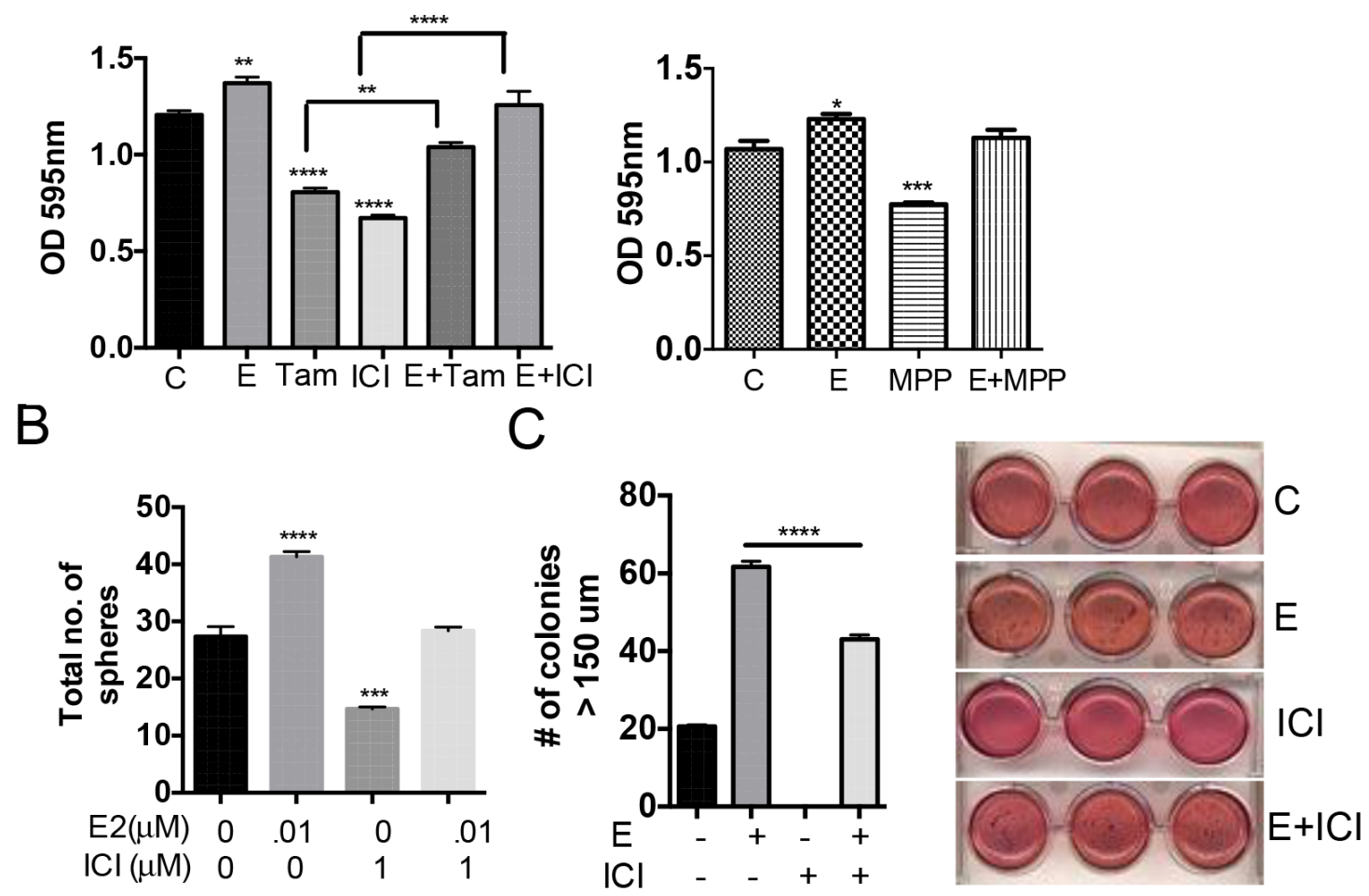

$\mathrm{D}$
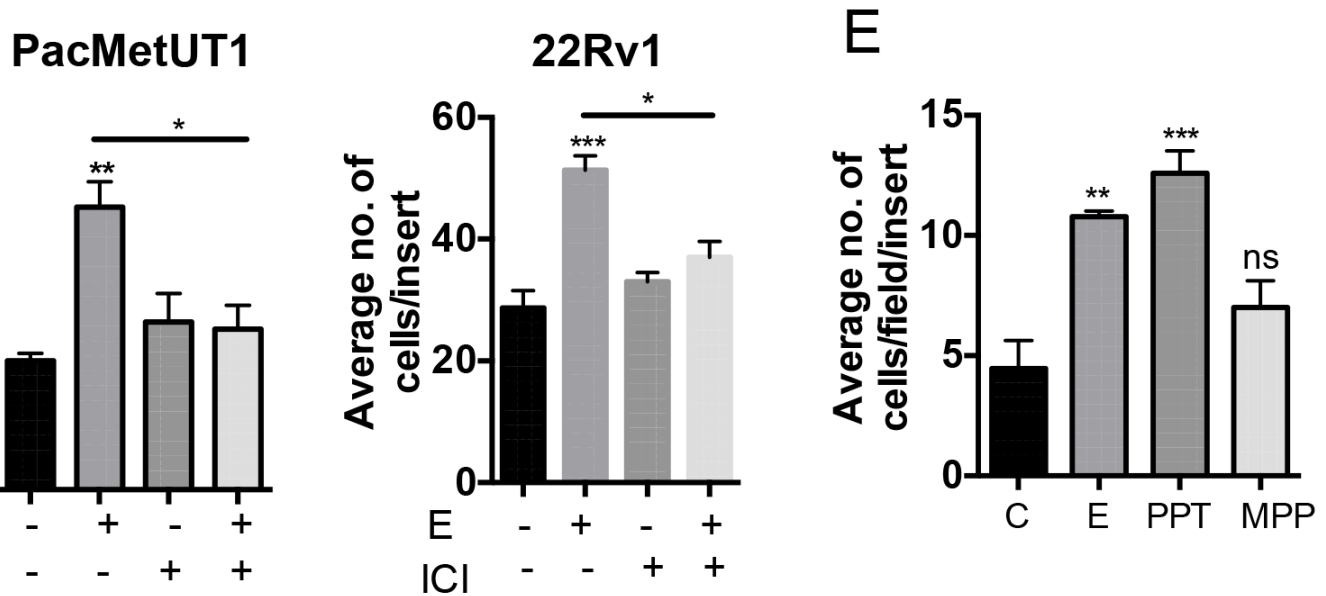

Figure 2: Estrogen increases anchorage-dependent and independent cell growth, migration and growth in suspension culture of prostate cancer cells. A. PacMetUT1 cells (1,000 cells/well) were treated with estrogen ( $10 \mathrm{nM})$, ICI (100 nM), Tamoxifen $(100 \mathrm{nM})$, or in combination for 5 days. Cell growth was analyzed by MTT assay. Data presented are mean \pm sem from five measurements. PacMetUT1 cells $(1,000$ cells/well) were treated with estrogen $(10 \mathrm{nM})$ and MPP $(100 \mathrm{nM})$, or in combination for 5 days. Cell proliferation was checked with MTT assay from six measurements. ${ }^{*} P<0.05,{ }^{*} P<0.01,{ }^{* * *} P<0.001$ and ${ }^{* * * *} P<0.0001$ with one-way ANOVA analysis. B. PacMetUT1 cells $(1,000$ cells $/ 100 \mu \mathrm{L})$ were plated in Epicult basal medium in a 96 -well low attachment plate. Cells were treated at the time of plating with estrogen $(0.01 \mu \mathrm{M})$, ICI $(1 \mu \mathrm{M})$, or in combination. After $48 \mathrm{~h}$, colonies were quantified and presented as mean \pm sem from triplicate wells. ${ }^{* * *} P<0.001$ and ${ }^{* * * *} P<0.0001$ with one-way ANOVA analysis. $\mathbf{C}$. Anchorage-independent growth of PacMetUT1 treated with estrogen $(10 \mathrm{nM})$, ICI $(1 \mu \mathrm{M})$, or in combination was measured after 7 days of growth in soft agar. Figures presented are from triplicate measurements with mean \pm sem. ${ }^{* * * *} P<0.0001$ with one-way ANOVA analysis. D. Migration of PacMetUT1 and 22Rv1 cells after treatment with estrogen $(10 \mathrm{nM})$, ICI $(100 \mathrm{nM})$ and in combination were counted in whole inserts after $18 \mathrm{~h}$. Data presented are mean \pm sem from triplicate wells. ${ }^{*} P<0.05, * * P<0.01$ and ${ }^{*} * * P<0.001$ with one-way ANOVA analysis. E. Migration of PacMetUT1 cells after treatment with estrogen $(10 \mathrm{nM})$, PPT and MPP $(100 \mathrm{nM})$ after $18 \mathrm{~h}$ were counted in five high power fields (HPF) per well. Data presented are mean \pm sem from triplicate wells. ${ }^{*} P<0.05,{ }^{*} P<0.01$ and $* * * P<0.001$ with one-way ANOVA analysis. ns denotes no statistical difference. 
effect (Figure 2E) as was observed with ICI (Figure 2D). These results again indicate the involvement of ER $\alpha$ in driving the malignant properties of prostate cancer cells.

\section{Estrogen/ER $\alpha$ signaling induces epithelial-to- mesenchymal transition}

Epithelial-to-mesenchymal transition (EMT) is a developmental process involved in cell differentiation, migration, and morphogenesis. During tumor progression, local microenvironmental factors in a primary tumor activate the EMT program in cancer cells, which triggers tumor cell invasion [32]. We noticed a change in morphology of PacMetUT1 cells with estrogen resembling the EMT process (Figure 3A). This was confirmed by a down-regulation in E-cadherin expression and an increase in Snail upon estrogen treatment (Figure 3B-3C). There was a decrease in E-cadherin mRNA expression after both 48 and 72 hours of treatment with estrogen, and an upregulation in Vimentin mRNA level, which is a mesenchymal marker (Figure 3D). These results indicate that estrogen signaling can stimulate EMT of the prostate cancer cells, likely through ER $\alpha$ as ERß was shown to inhibit EMT in earlier studies [33]. To test this hypothesis, we stably knocked down ER $\alpha$ in PacMetUT1 with two different shRNA sequences delivered by a lentiviral vector. As shown in Figure 3E, shRNA2 was more effective in knocking down ER $\alpha$ expression than shRNA1. Thus, shRNA2-transfected PacMetUT1 was used in subsequent experiments. The level of ERß was not altered when ER $\alpha$ was knocked down. ER $\alpha$ knockdown with shRNA2 moderately reduced the growth rate of PacMetUT1 cells when compared to the control and shRNA1 cells (Figure $3 F)$. Interestingly, estrogen mediated down-regulation in E-cadherin was completely abrogated in ER $\alpha$ knockdown PacMetUT1 cells (Figure 3G). Instead, we observed an induction in the basal level of E-cadherin with ER $\alpha$ knock down (Figure 3G). Similar effects were observed in both PacMetUT1 and LNCaP cells treated with ICI, which increased E-cadherin and decreased Snail or Vimentin (Figure $3 \mathrm{H}$ ). All these results confirm the involvement of ER $\alpha$ signaling in estrogen-induced EMT.

\section{Estrogen/ER $\alpha$ signaling induces osteoblast-like features in prostate cancer cells}

Because estrogen/ER $\alpha$ signaling induced EMT and is known to promote mesenchymal stem cell differentiation to osteoblasts and bone formation (our unpublished data, $[34,35]$, we hypothesized that estrogen/ER $\alpha$ signaling may induce prostate cancer cells to become bone-forming osteoblast-like cells, a phenomenon widely reported by others as osteomimicry phenotype [36, 37]. We found that, similar to the osteoblast precursor -human mesenchymal stem cells (hMSC), estrogen upregulated osteoblastic marker expression (Runx-2, Type I Collagen, and Osteocalcin) in prostate cancer cells when cultured in osteogenic differentiation medium (Figure 4A), but not in the regular proliferation medium (Supplementary Figure 1D). Conversely, stable knockdown of ER $\alpha$ in PacMetUT1 cells with shRNA and a transient knockdown of ER $\alpha$ in 22Rv1 and LNCaP with siRNA significantly reduced the expression of osteogenic markers (Figure 4B). Culture of PacMetUT1 and 22Rv1 cells in osteoblastic differentiation medium increased the activity of alkaline phosphatase, another marker of osteoblast differentiation (Figure 4C). In contrast, the alkaline phosphatase activity did not change in PC-3 cells (Figure 4C), which does not express ER $\alpha$ and induces osteolytic lesions [25]. Knockdown of ERa in PacMetUT1 attenuated the induction of the alkaline phosphatase activity in osteogenic medium (Figure 4D). These results suggest that prostate cancer cells have osteoblast-like properties as they express osteogenic markers that are further elevated when cultured in osteogenic medium and stimulated by estrogen signaling through ER $\alpha$. They are consistent with the published reports describing osteomimicry in prostate cancer cells $[36,37]$.

\section{ER $\alpha$ knockdown inhibits osteoblastic lesion formation in vivo}

Since estrogen signaling through ER $\alpha$ enhanced the mesenchymal and osteoblast-like features of PacMetUT1 cells, we next examined the role of ER $\alpha$ in osteoblastic tumorigenesis in vivo. The control and ER $\alpha$ knockdown PacMetUT1/Luc-GFP cells were injected into the right tibia of 5-week-old male nude mice at $1 \times 10^{5}$ cells/mouse. PBS was injected into the contralateral left tibia as control. Bioluminescence imaging revealed a slower growth rate of intratibia tumors formed by ER $\alpha$ knockdown cells than the control cells although the differences were not significant at all time points (Figure 5A). At the end of 7 weeks after tumor cell inoculation, we harvested the tibiae and lungs to check for bone remodeling and lung metastasis. Micro$\mathrm{CT}$ analysis showed a high intensity of trabecular bone in tibiae injected with cancer cells (Figure 5B) demonstrating the robust osteogenic activity of PacMetUT1 cells as previously published [31]. Furthermore, ER $\alpha$ knockdown in PacMetUT1 led to a remarkable reduction in trabecular bone formation (Figure 5B). We detected a reduced immunostaining of mouse specific type I collagen in the bone matrix (Figure 5C) and a significant reduction in bone volume (Figure 5D) in ER $\alpha$ knockdown tumor cells. The ER $\alpha$ knockdown in PacMetUT1 did not result in changes in AR or ER $\beta$ expression in the mouse tibia (Supplementary Figure 2A-2B). These results suggest that ER $\alpha$ expression in the PacMetUT1 cell is essential for its osteoblastic tumorigenic property. Consistent with the notion that EMT promotes metastasis, we detected metastasis to lungs by examining GFP-positive metastatic nodules under an epi-fluorescence microscope as done previously [31]. We observed a significant reduction of 
50\% $(P<0.05$, Fisher's Exact Test $)$ in lung metastasis incidence rate in $\mathrm{ER} \alpha$ knockdown group in comparison with the control group (Figure 5E).

\section{Treatment with ER $\alpha$ inhibitor ICI 182,780 inhibits osteoblastic bone formation}

As ER $\alpha$ in PacMetUT1 cells contributes to osteoblastic tumor formation, we next investigated the effect of pharmacological inhibition of ER $\alpha$ with ICI 182,780 on osteoblastic lesion formation. The male nude mice were injected with PacMetUT1/Luc-GFP cells in the right tibiae and PBS in the left tibiae, and treated with ICI at $5 \mathrm{mg} / \mathrm{kg}$ once a week for 7 weeks. There was no change in tumor growth rate in bone with ICI treatment (Figure 6A). However, there was a significant reduction in bone formation in the ICI treatment group with both radiographic imaging (Figure 6B) and histologic staining in comparison
A

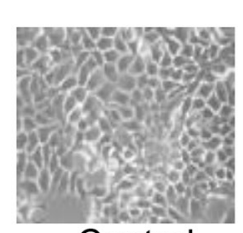

Control
B

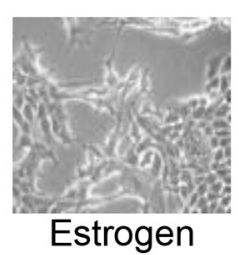

B

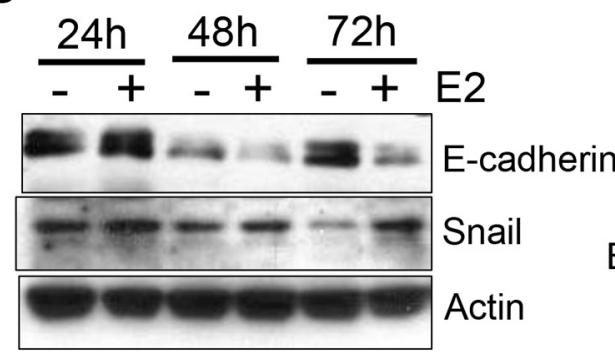

E

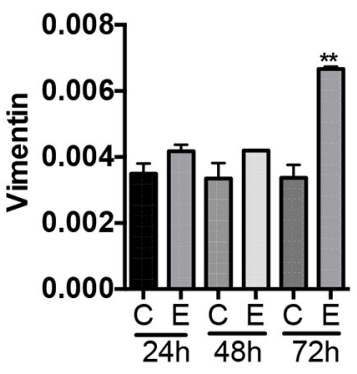

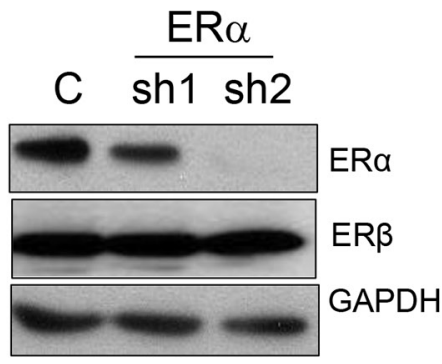

C

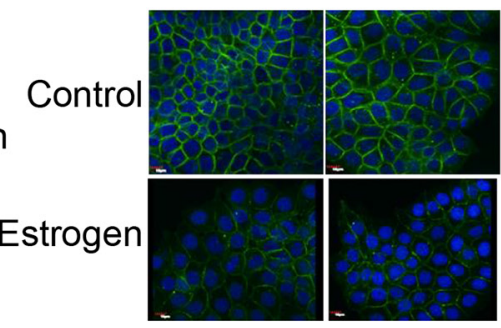

$\mathrm{F}$

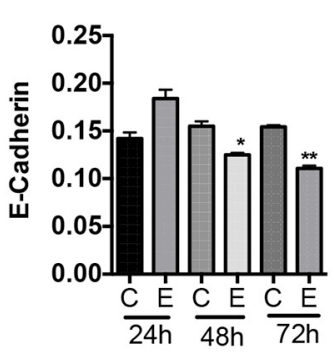

G

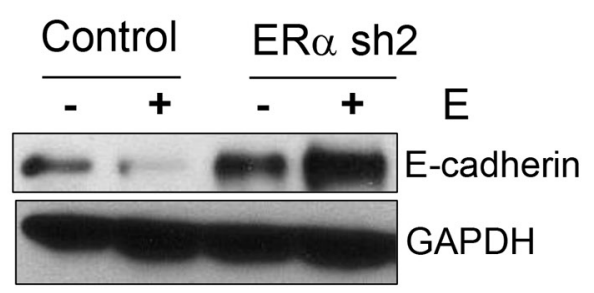

$\mathrm{H}$

PacMetUT1
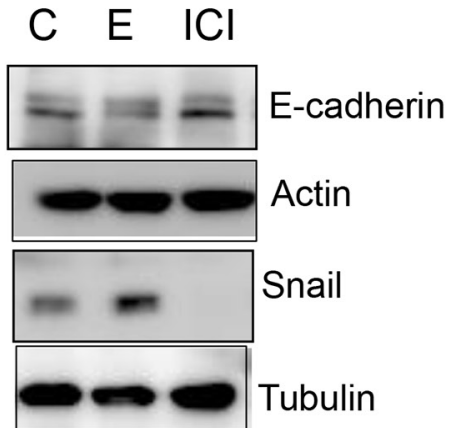

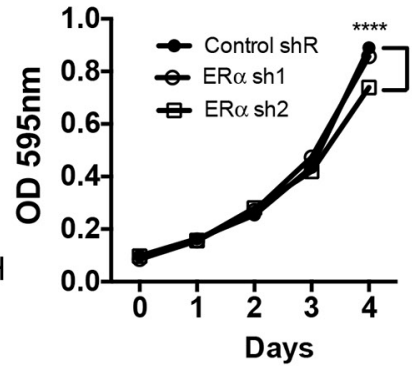


with the vehicle treated group (Figure 6C). There was a significant reduction in bone formation in ICI treated group with histomorphometry analysis (Figure 6D). Similar to the ER $\alpha$ knockdown, ICI treatment also significantly $(P<0.01$, Fisher's Exact Test) reduced lung metastasis incidence to $20 \%$ from $100 \%$ in the vehicle treated group (Figure 6E). All these results indicate a positive role of ER $\alpha$ in promoting bone formation and lung metastasis in PacMetUT1 cell model in vivo and the potential utility of $\mathrm{ER} \alpha$ inhibitors for the intervention of osteoblastic lesion formation.

\section{ER $\alpha$ mediates cross-talk between prostate cancer cells and pre-osteoblasts}

The osteomimicry properties of prostate cancer cells led us to examine whether cancer cells themselves could form calcium nodules in vitro and trabecular bone in vivo. However, we did not observe a positive alizarin red staining for mineralization when PacMetUT1 cells were cultured in mineralization-inducing medium for 3 weeks. This is in contrast to some of the published reports observing a positive staining with other prostate cancer cells $[38,39]$. Consistent with our in vitro findings, we did not detect a positive staining of human type I collagen in tibiae sections with new trabecular bones after PacMetUT1 injection (Figure 7A). Although PacMetUT1 cells were stained positive with anti-human type I collagen antibody (Figure 7A) suggesting that tumor cells themselves do not form bones. Hence, we tested the possibility that tumor cells could induce pre-osteoblasts to form excessive amount of osseous tissues. Indeed, co-culture of hMSCs with prostate cancer cells upregulated osteogenic markers
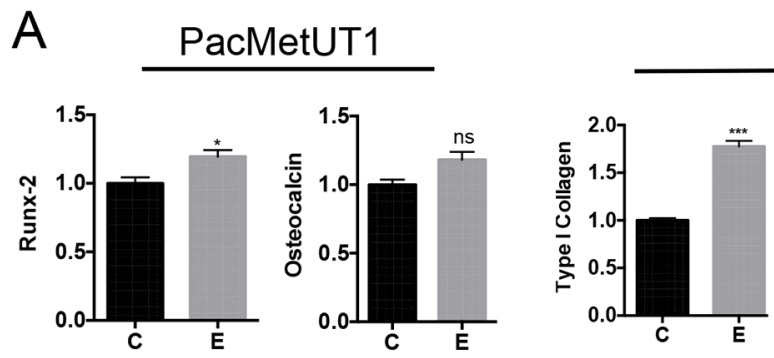

LNCaP
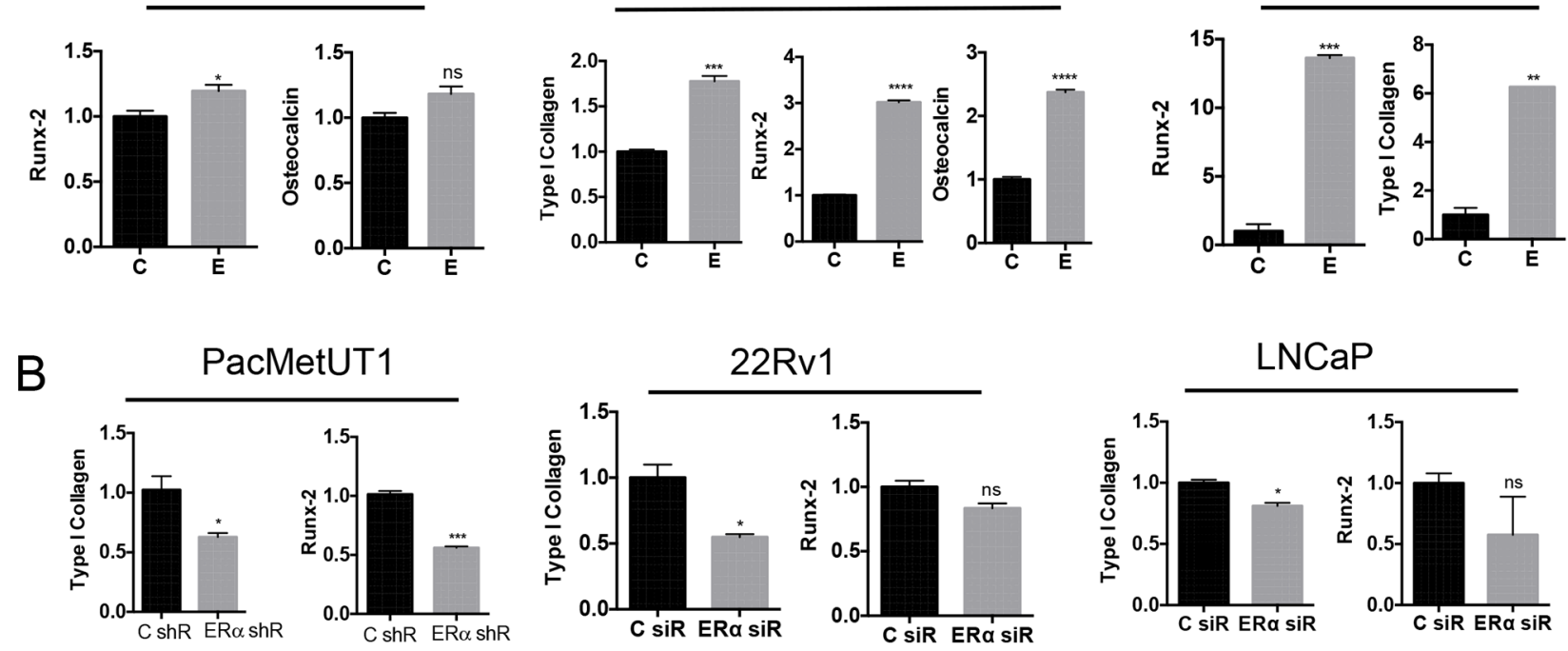

PacMetUT1
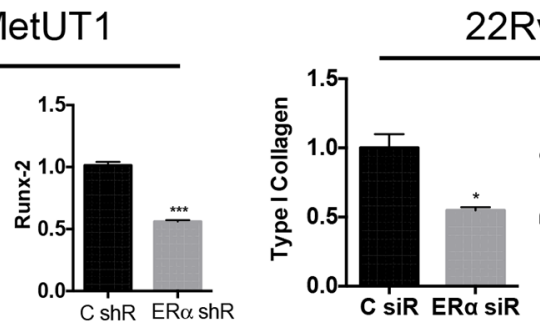

$22 \operatorname{Rv} 1$
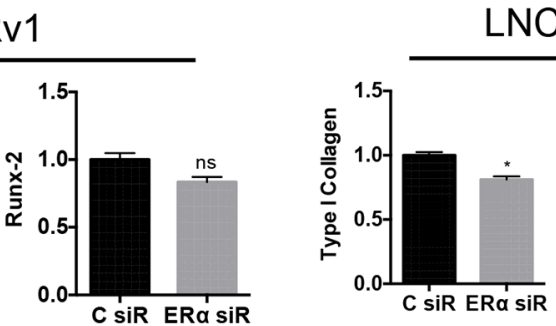

LNCaP

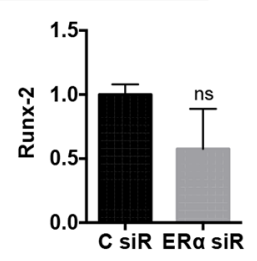

$D$

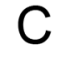

C

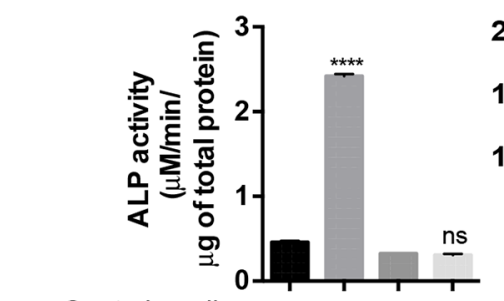

Control medium + - + -

Osteogenic medium $\frac{-}{\text { PacMetUT1 PC-3 }}$

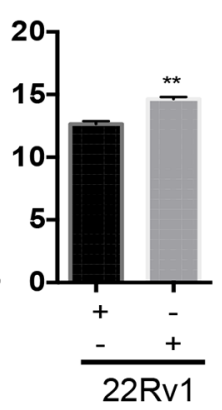

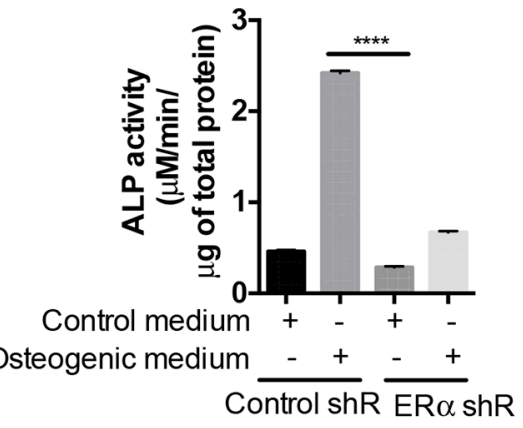

Figure 4: Estrogen/ERa signaling induces osteoblast-like properties in prostate cancer cells. A. Estrogen induces osteogenic markers determined by real-time RT-PCR in PacMetUT1, LNCaP and hMSC cells when cultured in osteogenic differentiation medium for 5 days. B. ER $\alpha$ knockdown in prostate cancer cells reduces osteogenic marker expression in cells as determined by real-time RT-PCR analysis. ${ }^{*} P<0.05,{ }^{*} P<0.01,{ }^{*} * P<0.001$ and $* * * * P<0.0001$ with one-way ANOVA analysis. C. Alkaline phosphatase activity assay was performed in the lysate of PacMetUT1, PC-3 and 22Rv1 cells after 4 days of culture in the presence and absence of osteogenic differentiation medium. Results are normalized to total protein concentration. D. Alkaline phosphatase activity was measured in control and ER $\alpha$ knockdown PacMetUT1 cells in the presence and absence of osteogenic differentiation medium. Data are presented as mean \pm sem from three measurements for the alkaline phosphatase assays. ${ }^{*} P<0.05, * * P<0.01, * * * P<0.001$ and $* * * * P<0.0001$. 
in hMSCs (Figure 7B). The knockdown of ER $\alpha$ in cancer cells decreased their potency in stimulating osteogenic marker expression in hMSCs under co-culture condition (Figure 7C). Interestingly, there was a reduced expression of osteocalcin in the tibiae injected with $\mathrm{ER} \alpha$ knock down PacMetUT1 tumors (Figure 7D). These results suggest that the tumor cells can induce osteoblast differentiation and bone formation by pre-osteoblasts by secreting factors that are regulated by estrogen/ $\mathrm{ER} \alpha$.

\section{DISCUSSION}

Metastasis is the primary reason of mortality in cancer. Prostate cancer patients who are in the advanced stage of the disease often develop bone metastasis that is predominantly osteoblastic. The mechanisms of osteoblastic lesion development are not well defined. A variety of factors have been implicated as potential mediators such as endothelin-1 [40], fibroblast growth factors (FGFs), bone morphogenetic proteins (BMPs)
[41], and Wnts [42]. Other factors, such as parathyroid hormone-related protein (PTHrP) and RANKL have been reported to mediate osteolytic metastasis of prostate cancer [43]. One major challenge in the field is the lack of model systems that mimics osteoblastic lesions [44, 45]. We have established a novel osteoblastic model in vivo using a human prostate cancer derived cell line, PacMetUT1 [31]. In the present study, we took advantage of this system to discover a new role of estrogen and ER $\alpha$ in osteoblastic tumorigenesis.

Estrogens have been considered to be significant risk factors in the development of benign prostatic hyperplasia and prostate cancer. The presence of estrogen receptors in the prostate tissue suggests that estrogens can have functional roles in the prostate. It has been widely reported that ERß is the predominant subtype, expressed in the majority of prostate epithelial cells, whereas ER $\alpha$ is expressed typically in the prostate stromal cells. ER $\alpha$ positive cells have also been found in the hyperplastic epithelium of the prostatic ducts, but its functional role
A

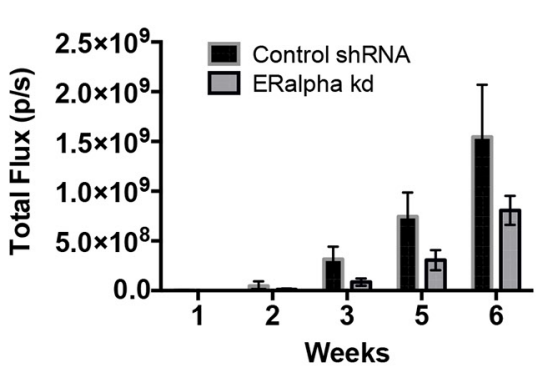

B
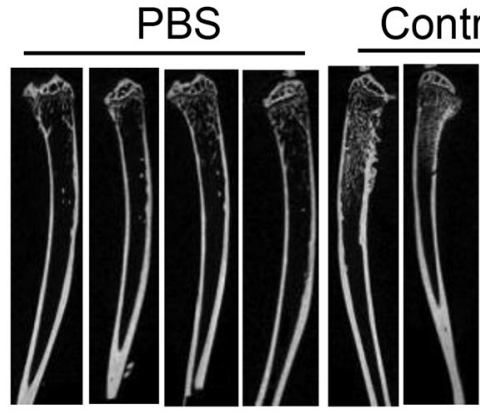

Type I
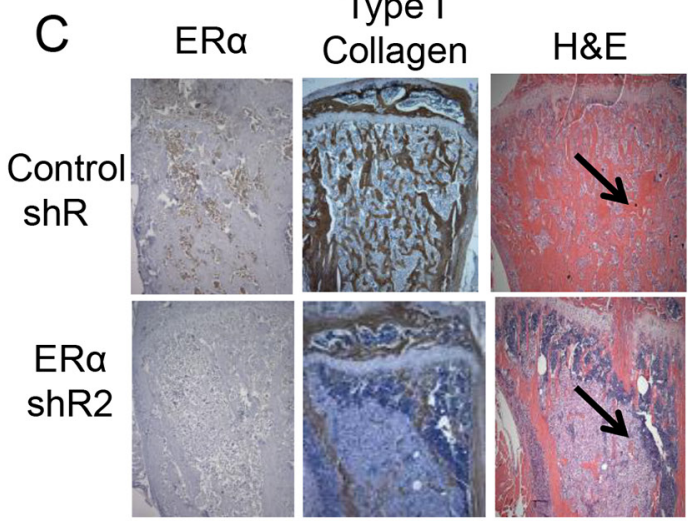

D

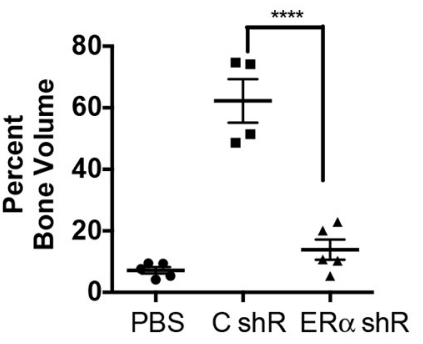

$E$

\begin{tabular}{|c|c|}
\hline Group & $\begin{array}{c}\text { Lung } \\
\text { Metastasis }\end{array}$ \\
\hline Control shR & $100 \%(9 / 9)$ \\
\hline ERa shR & $50 \%(4 / 8)$ \\
\hline
\end{tabular}

Figure 5: ERa knockdown in PacMetUT1 cells reduces osteoblastic lesion formation and lung metastasis. A. Total photon flux of intratibia tumors was obtained through whole body bioluminescence imaging of mice inoculated with PacMetUT1 control and ER $\alpha$ knockdown cells. Data are presented as mean \pm sem from nine control and eight ER $\alpha$ knockdown mice containing tumors. B. Representative micro-CT images are presented for tibiae injected with PBS or PacMet/Luc-GFP cells transfected control or ER $\alpha$ shRNA. C. Representative images of immunohistochemical staining of tibia sections for ER $\alpha$ and Type I collagen are presented. Corresponding H\&E stained images are also shown. Arrow indicates PacMetUT1 tumor cells that are less stained than the bone tissue. D. The total bone volume expressed as percentage of a defined section of tibia volume was plotted from micro-CT imaging data. Data are presented as mean \pm sem from 4-5 tibiae in each group. $* * * * P<0.0001$ with one-way ANOVA. E. Lung metastasis incidence in the control and ER $\alpha$ knockdown group was confirmed in the excised whole lungs with green fluorescence imaging for GFP positive tumor colonies after the termination of experiment at 7 weeks. 
A

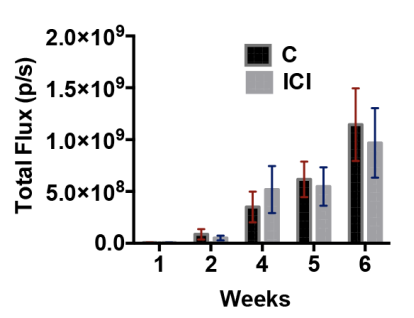

B

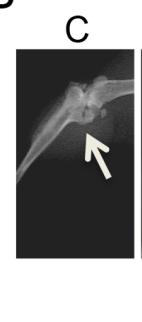

$\mathrm{ICl}$

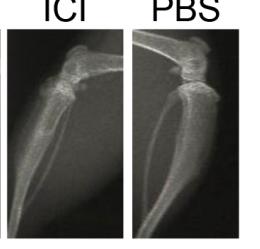

C New Bone

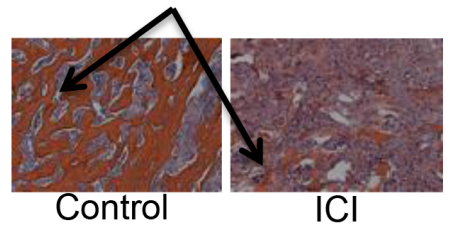

D

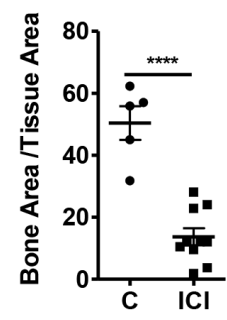

$E$

\begin{tabular}{|c|c|}
\hline Group & $\begin{array}{c}\text { Lung } \\
\text { Metastasis }\end{array}$ \\
\hline Control & $5 / 5(100 \%)$ \\
\hline $\mathrm{ICl}$ & $2 / 10(20 \%)$ \\
\hline
\end{tabular}

Figure 6: Treatment with pharmacological inhibitor ICI reduces osteoblastic lesion development and lung metastasis. A. Whole body bioluminescence imaging was performed to measure tumor growth over time in the tibiae. B. and $\mathbf{C}$. Representative images from X-ray radiography and H\&E staining are shown. Arrow shows new bone formation inside the tibia. D. Bone area to total tissue area was quantified with BIOQUANT analysis software. Data are presented as mean \pm sem with each dot representing one tibia. E. Lung metastasis incidence was confirmed in the excised whole lungs after the termination of experiment at 7 weeks. $* * * * P<0.0001$.

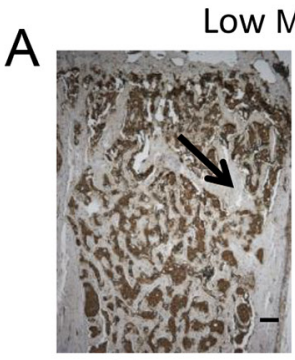

Human

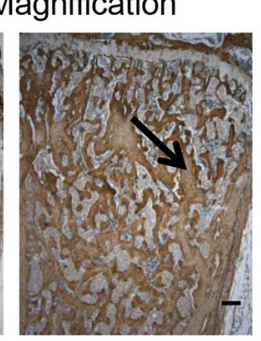

Mouse
C

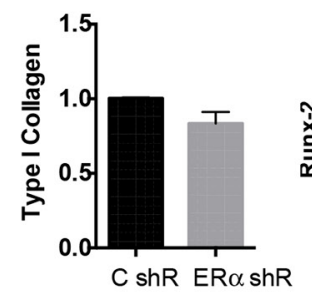

Co-culture of hMSC with PacMetUT1 cells

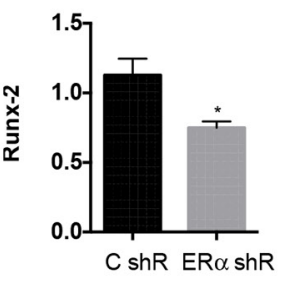

High Magnification

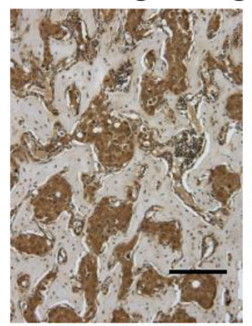

Human

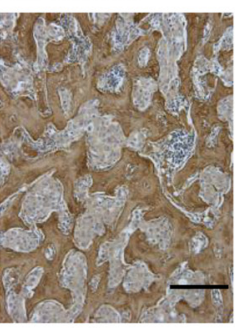

Mouse

B

Co-culture of hMSC with LNCaP cells

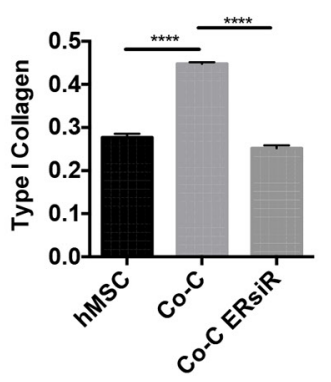

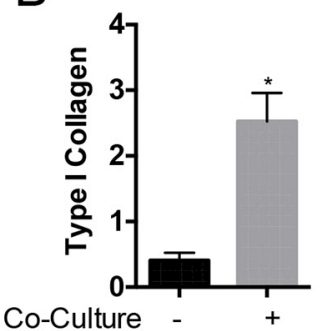

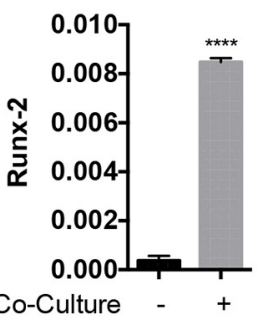

$\mathrm{D}$

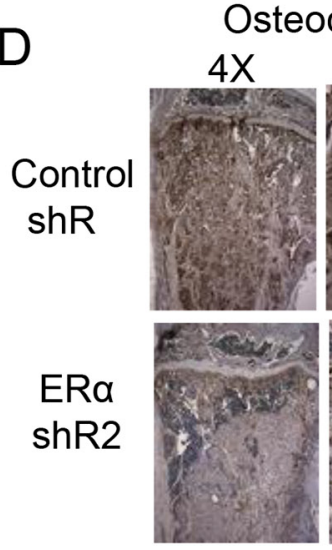

Osteocalcin

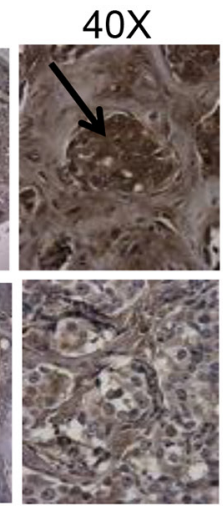

Figure 7: ER $\alpha$ knockdown in prostate cancer cells attenuates their ability to induce osteoblastic marker expression in pre-osteoblasts. A. Immunohistochemistry with human and mouse Type I Collagen antibody in two consecutive tibia section with PacMetUT1-formed tumor indicates new bone formed is stained only with mouse collagen, while tumor cells are stained with human collagen with little overlapping staining. Scale bar $=200 \mu \mathrm{m}$. B. Osteogenic markers, Type I collagen and Runx-2, in hMSC cells were measured with real-time RT-PCR after being co-cultured with PacMetUT1 cells for 4 days. C. Cells with or without ER $\alpha$ knockdown were co-cultured with hMSC for 4 days. Osteogenic markers were then measured in hMSC with real-time RT-PCR. D. Immunohistochemistry for osteoblast marker (osteocalcin) was performed in tibiae injected with control and ER $\alpha$ knockdown PacMetUT1/Luc-GFP cells. Arrow indicates a positive staining. Data in the panel $\mathrm{B}$ and $\mathrm{C}$ are presented as mean \pm sem from triplicate measurements. ${ }^{*} P<0.05,{ }^{* *} P<0.01$ and $* * * * P<0.0001$ 
remains undefined [46]. Studies by Bankoff et al. showed $\mathrm{ER} \alpha$ expression in prostate cancer and in premalignant prostatic lesions [27]. Due to our limited understanding of $\mathrm{ER} \alpha$ contribution in prostate cancer, we investigated the role of estrogen and ER $\alpha$ in prostate cancer malignancy. $\mathrm{ER} \alpha$ is expressed in prostate cancer cells at varying levels with PacMetUT1, C4-2, 22Rv1 and LNCaP cells expressing higher level of ER $\alpha$ compared to BPH-1. We further found that estrogen had an oncogenic effect on prostate cancer cells by increasing cell migration and anchorage-independent growth. It was shown previously that stimuli such as TGFß and hypoxia could inhibit ERß expression in prostate cancer cells, and the loss of ERß promoted EMT [33]. We observed a downregulation in E-cadherin and an increased Snail and Vimentin expression in prostate cancer cells with estrogen treatment. The knockdown of ER $\alpha$ in PacMetUT1 abrogated these effects of estrogen suggesting that the estrogen induced EMT is mediated by ER $\alpha$. To further check the role of ER $\alpha$ in osteoblastic lesion formation, we injected the control and ER $\alpha$ knockdown PacMetUT1 cells directly in the tibia of male nude mice. The micro$\mathrm{CT}$ analysis of tibiae sections showed significant reduction in bone formation by the PacMetUT1 cells when ER $\alpha$ was knocked down suggesting that ER $\alpha$ expression in PacMetUT1 is essential for osteoblastic tumor formation in vivo. Systemic treatment of mice with an ER $\alpha$ inhibitor, ICI 182,780 , also significantly reduced osteoblastic tumor formation. These results suggest that the blockade of ER $\alpha$ signaling may prevent prostate cancer-induced bone impairment and maintain bone health. This notion is consistent with a recent phase III clinical trial using a selective estrogen receptor modulator Toremifene in prostate cancer demonstrating a significant decrease in the incidence of new vertebral fractures in men receiving androgen deprivation therapy for prostate cancer [11].

Some studies suggest that tumor cells can survive and proliferate in bone tissues by acquiring a bone-cell phenotype and osteoblastic features termed osteomimicry $[36,47]$. We also observed expression of osteogenic markers and alkaline phosphatase activity when prostate cancer cells were cultured in osteogenic differentiation medium. Estrogen enhanced the increase in osteogenic markers whereas ER $\alpha$ knockdown attenuated the osteoblast-like features in prostate tumor cells. However, analysis of tibiae sections in PacMetUT1 osteoblastic in vivo model revealed staining of newly formed bone tissues with mouse collagen antibody. This suggests that the human prostate cancer cells themselves did not form bones, but likely induced the differentiation of mouse pre-osteoblasts. Indeed, co-culture of human osteoblast precursor cells (hMSC) with prostate cancer cells induced osteoblastic marker expression in hMSCs. Inhibition of $\mathrm{ER} \alpha$ in prostate cancer cells further abrogated this effect. Further studies are required to delineate the key factors involved in the tumor-bone stroma crosstalk that is affected by estrogen/ ER $\alpha$ signaling. Since PacMetUT1 has unique features in expressing low AR and high levels of ER $\alpha$, we queried the cancer genome atlas database (TCGA) to check how many tumor samples have similar expression patterns. Out of 419 tumor samples, we found that 43 samples have high levels of ER $\alpha$ compared to AR, which represents about $10.26 \%$ of the total tumor population examined (supplementary Figure 3A-3G).

Pulmonary metastasis commonly develops in prostate cancer patients who have bone metastasis [48]. We found a significant reduction in lung metastasis in vivo with both genetic and pharmacological inhibition of ER $\alpha$ in tumor cells. This could be due to the reduced ability of ER $\alpha$ knockdown PacMetUT1 to invade and migrate into the bone marrow as our in vitro studies suggested that the blockade of ER $\alpha$ signaling inhibited EMT, which is known to promote tumor cell migration and invasion.

In summary, our study revealed a novel role of estrogen signaling in promoting osteoblastic tumor formation in human prostate cancer cell lines. This oncogenic role of estrogen is mediated by ER $\alpha$. Thus, inhibition of ER $\alpha$ signaling in prostate cancer cells may be a novel therapeutic strategy to inhibit the osteoblastic lesion development in patients with advanced stage prostate cancer.

\section{MATERIALS AND METHODS}

\section{Cell cultures}

LNCaP, 22Rv1, MDA-MB-231, MCF-7 and MDA-PCa- $2 b$ cell lines were purchased from American Type Culture Collection (ATCC, Manassas, VA, USA). These cells were cultured in medium recommended by ATCC. BPH-1 cell line was obtained from Dr. Scott Lucia's laboratory and cultured in a RPMI1640 medium containing $10 \%$ fetal bovine serum. PacMetUT1 was isolated from the lymph node metastasis of a 57year old prostate cancer patient at our university [49]. Freshly isolated human bone marrow mononuclear cells, containing BM-MSCs (primary cells) from 20-25 year old donors, were purchased from Lonza (Walkersville, MD) and cultured in alpha-minimum essential medium (MEM; Gibco BRL, Life Technologies, NY, USA) supplemented with $15 \%$ fetal bovine serum (FBS, Gibco). All the cells were maintained at $37^{\circ} \mathrm{C}$ in a $5 \% \mathrm{CO}_{2}$ humidified incubator.

\section{Chemicals}

Estrogen (17ß-estradiol) and tamoxifen were purchased from Sigma (St. Louis, MO, US), ICI 182,780, 1,3-Bis(4-hydroxyphenyl)-4-methyl-5-[4-(2piperidinylethoxy)phenol]-1H-pyrazole dihydrochloride 
(MPP dihydrochoride), and 4,4',4"-(4-Propyl-[1H]pyrazole-1,3,5-triyl)trisphenol (PPT) were purchased from Tocris Bioscience (Bristol, United Kingdom).

\section{In Vitro luciferase assay}

For transient transfection, cells were seeded in triplicates in a 12-well plate at a density of 1.5-2.0 $\times 10^{5}$ cells/well in the culture medium containg $10 \%$ charcoalstripped fetal bovine serum. When the cultures were $80 \%$ confluent, they were co-transfected with $500 \mathrm{ng}$ of an estrogen responsive promoter-luciferase construct (ERELuc) and $100 \mathrm{ng}$ of a $\beta$-galactosidase expression plasmid using $1.8 \mu \mathrm{L}$ of Lipofectamine 2000 (Invitrogen, Carlsbad, CA, USA). After 5 hours, the medium was replenished containing estrogen $(10 \mathrm{nM})$ or vehicle. Luciferase assay was performed as described previously [31, 50] after 24 hour of incubation.

\section{Cell proliferation assay}

Cells were plated in 96-well plate at 2,000 cells per well in five-well replicate. After 4 hours, cells were treated with different chemicals for 5 days. MTT assays were used for quantifying numbers of viable cells with a Biotek plate reader (Biotek Instruments, Winooski, VT, US) as described previously [31].

\section{Western blot analysis}

Cells after harvesting were lysed in Laemmli buffer containing protease inhibitors and processed as described previously [31]. The antibodies to ER $\alpha$ and ER $\beta$ were purchased from Millipore, to GAPDH from Calbiochem (Billerica, MA, US), to actin from Sigma (St. Louis, MO, US), to E-cadherin from BD Biosciences (San Jose, CA, US), and to Snail from Abcam (Cambridge, MA, US).

\section{Alkaline phosphatase activity assay}

Cells were seeded in 12-well plates, proliferation and osteogenesis induction medium (Chemicon, EMD Millipore, Billerica, MA, USA), which consisted of 0.1 $\mu \mathrm{M}$ dexamethasone, $0.2 \mathrm{mM}$ ascorbic acid-2-phosphate and $10 \mathrm{mM}$ Glycerol-2-phosphate. Medium was replenished every 2 days. ALP activity was measured after 5 days using Quantichrom alkaline phosphatase assay kit (DALP - 250, BioAssay Systems, Hayward, CA, USA).

\section{Animal experiments}

Four- to five-week old male athymic nude mice were purchased from Harlan Sprague-Dawley, Inc. (Indianapolis, IN, US). The animal protocol was approved and monitored by the Institutional Animal Care and Use
Committee. Animals were housed under the care and supervision of Laboratory Animal Research Facility at the University of Texas Health Science Center, San Antonio, Texas, US.

\section{Intratibia injections}

Animal surgery was performed under constant anesthesia with isofluorane inhalation. PacMetUT1 cells $\left(1 \times 10^{5}\right.$ in $10 \mu \mathrm{L}$ PBS $)$ were inoculated into the bone marrow area of right tibiae through a pre-made hole using a Hamilton syringe fitted with 27 -gauge needle as described previously [31]. The left tibiae were injected with PBS as controls for the surgery.

\section{Bioluminescence imaging analysis}

After mice were anesthetized with isofluorane inhalation, D-luciferin (Xenogen) was injected i.p. at $75 \mathrm{mg} / \mathrm{Kg}$ body weight in PBS with a $1 \mathrm{~min}$ interval for each mouse. Ten minutes later, bioluminescence images were acquired with IVIS spectrum Imaging system (Xenogen) at $1 \mathrm{~min}$ interval for each mouse as described previously [31].

\section{Radiographic analysis}

Mice were exposed with an X-ray at $35 \mathrm{KVP}$ for 5 sec by using a Faxitron Digital Radiographic Inspection unit against the detector as described [51].

\section{Bone histomorphometry analysis}

Bone tissues were fixed in $70 \%$ ethanol for 24 $48 \mathrm{~h}$ at room temperature, decalcified in 10\% EDTA, and embedded in paraffin. Sections were stained with hematoxyoin and esosin, orange $\mathrm{G}$ and phloxine. The trabecular bone and tumor areas in a tibia section were examined under a Nikon Eclipse E800 microscope equipped with a QImaging QICAM-F fast color digital camera and quantified using Bioquant Osteo System (Bioquant Image Analysis Corporation, Nashville, TN, US) as was described previously [31].

\section{MicroCT analysis}

Micro-Computed tomography $(\mu \mathrm{CT})$ was performed on the tibia using a desktop SkyScan 1172 (Bruker, Aartselaar, Belgium) system. Each specimen was submerged in $70 \%$ ethanol, positioned with the proximal tibia pointing upward and the tube was sealed with parafilm. Samples were scanned at $60 \mathrm{kV}, 167 \mu \mathrm{A}$ beam intensity, $10 \mu \mathrm{m}$ image pixel size, $0.7^{\circ}$ rotation step, 4 frames averaging, and a 700-millisecond exposure time at each step. The structural properties of the trabecular 
bone were evaluated in the proximal metaphysis. The volume of interest (VOI) started $0.5 \mathrm{~mm}$ distally from the proximal growth plate and continued distally for 1.5 $\mathrm{mm}$. The trabecular boundary was outlined manually. 3D morphometric analyses were performed on the trabecular VOIs.

\section{RNA isolation and real time PCR analysis}

Cells were lysed in TRIzol reagent (Sigma) for dissociation of any RNA-protein complexes and RNA was isolated as previously described [52]. Primer sequences are available upon request.

\section{Co-culture assay}

Human mesenchymal stem cells were seeded in 24well plates, grown for $24 \mathrm{~h}$, and then co-cultured with or without control and ER $\alpha$ knockdown PacMetUT1/LucGFP, 22Rv1 or LNCaP cells in cell culture inserts $(1.0-\mu \mathrm{m}$ pore size, Becton Dickinson, Durham, NC, USA). After 4 days of co-culture, inserts containing prostate cancer cells were removed and total RNA was isolated from hMSC cells for quantitative real-time PCR analysis.

\section{Migration assay}

Cells were seeded in the upper 24-well Boyden chambers with 8 micron-size inserts (BD Biosciences, Durham, NC, USA) with or without treatments in serumfree containing medium. Serum-containing medium was added to the lower chamber. Cell migration was counted after 18 hours by fixing and staining the cells with Hema 3 Stain 18 kit (Fischer Scientific, Waltham, MA, USA) according to the manufacturer's protocol.

\section{Immunohistochemistry}

Bone tissue sections were rehydrated through xylene and graded ethanol, incubated in the proteinase $\mathrm{K}(20 \mu \mathrm{g} / \mathrm{ml})$ for $10 \mathrm{~min}$ and then sections were blocked for endogenous peroxidase with $3 \%$ hydrogen peroxide (Thermo Fisher Scientific, Waltham, MA, USA) for 30 min in room temperature. Sections were permeabilized and blocked in 10\% goat serum for $1 \mathrm{hr}$. The primary antibodies were anti-collagen I (1:600, ab138492 and ab21286, Abcam, Cambridge, MA, USA) diluted in the $5 \%$ goat serum and incubated at $4^{\circ} \mathrm{C}$ overnight. Sections were then incubated with a biotinylated goat anti-rabbit antibody (BD Pharmingen, San Diego, CA, USA). For detection, Streptavidin-Horseradish Peroxidase and DAB Substrate Kit (BD Pharmingen, San Diego, CA, USA) were used and the counterstain was done with hematoxylin. For osteocalcin (AbD Serotec 7060-1815, 1:1200 dilution), androgen receptor (Santa Cruz, sc-816,
1: 200) and ERß (Santa Cruz, sc-8974) antigen retrieval was done with $0.5 \%$ trypsin at $37^{\circ} \mathrm{C}$ for $30 \mathrm{~min}$ and for estrogen receptor alpha (Santa Cruz 8002, 1:150), antigen retrieval was done in $10 \mathrm{mM}$ sodium citrate, $\mathrm{pH} 6$, at $95^{\circ} \mathrm{C}$ for $15 \mathrm{~min}$.

\section{The cancer genome atlas database (TCGA) data analysis}

Level3 data of gene expression reads count estimated by RSEM [53] of 419 tumor and 52 normal samples of prostate adenocarcinoma (PRAD) in TCGA were downloaded. Reads Per Kilobase of transcript per Million mapped reads (RPKM) values of gene $g$ in sample $s$ were calculated from estimated reads counts by the modified formula below [54]:

$$
\operatorname{RPKM}_{g, s}=\frac{\text { ReadCount }_{g, s} \times 10^{9}}{\left(\sum_{\text {in }_{s}} \text { ReadCount }_{g, s}\right) \times \text { GeneLength }_{g}}
$$

Gene lengths are the summed lengths of reduced exons from annotation package Homo.sapiens in Bioconductor/R. Log2 (RPKM + 1) values were used as Log2 Expression values to compare gene expression across samples. Gene expression values of ESR1, ESR2 and AR were used for generating Heatmaps using heatmap.2 from package gplots/R. Sample distance were calculated in Pearson Correlation and hierarchical clustering were performed in complete linkage method. Significance of difference between gene expression levels of ESR1 and AR were called based on cutoff at one-tail $p$ value 0.1 on the transformed $\mathrm{z}$ scores.

\section{Statistical analysis}

Two-tailed Student's $t$-test was used to compare two groups. One-way analysis of variance was used for analyzing data when more than two groups were used with Tukey-Kramer post hoc test. Results are expressed as mean \pm sem. $P<0.05$ was considered to be statistically significant.

\section{ACKNOWLEDGMENTS}

We thank the institutional cores of Optical Imaging, Pathology, Micro-Computed Tomography for their assistance in obtaining part of the presented data. The authors also thank Dr. Brian Rabinovich at MD Anderson Cancer Center for the pLV411G effLuc-flagIRES-hrGFP vector, Dr. John A Copland for the lentiviral ER $\alpha$ shRNA constructs and Dr. Scott Lucia at University of Colorado Health Science Center for providing us with BPH-1 cells. 


\section{CONFLICTS OF INTEREST}

The authors declare no potential conflicts of interest.

\section{FUNDING}

This study was in part supported by RP120290IIRA from Cancer Prevention and Research Institute of Texas (CPRIT), and R01CA172886 from NIH, and the Cancer Therapy and Research Center at the University of Texas Health Science Center at San Antonio (UTHSCSA) through the NCI Cancer Center Support Grant 2 P30 CA054174.

\section{REFERENCES}

1. Siegel R, Ma J, Zou Z and Jemal A. Cancer statistics, 2014. CA: a cancer journal for clinicians. 2014; 64:9-29.

2. Bosland MC. The role of steroid hormones in prostate carcinogenesis. Journal of the National Cancer Institute Monographs. 2000; :39-66.

3. Xiang-Yun L, Ying-Wen X, Chen-Jing X, Jiu-Jiu W, Qi $\mathrm{P}$, Bo $\mathrm{G}$ and $\mathrm{Zu}-Y$ ue $\mathrm{S}$. Possible mechanism of benign prostatic hyperplasia induced by androgen-estrogen ratios in castrated rats. Indian journal of pharmacology. 2010; 42:312-317.

4. Citrin DL, Resnick MI, Guinan P, al-Bussam N, Scott M, Gau TC and Kennealey GT. A comparison of Zoladex and DES in the treatment of advanced prostate cancer: results of a randomized, multicenter trial. Prostate. 1991; 18:139-146.

5. Nevalainen MT, Valve EM, Makela SI, Blauer M, Tuohimaa PJ and Harkonen PL. Estrogen and prolactin regulation of rat dorsal and lateral prostate in organ culture. Endocrinology. 1991; 129:612-622.

6. Martikainen P, Harkonen P, Vanhala T, Makela S, Viljanen $\mathrm{M}$ and Suominen J. Multihormonal control of synthesis and secretion of prostatein in cultured rat ventral prostate. Endocrinology. 1987; 121:604-611.

7. Risbridger GP, Wang H, Frydenberg M and Cunha G. The metaplastic effects of estrogen on mouse prostate epithelium: proliferation of cells with basal cell phenotype. Endocrinology. 2001; 142:2443-2450.

8. Leav I, Merk FB, Kwan PW and Ho SM. Androgensupported estrogen-enhanced epithelial proliferation in the prostates of intact Noble rats. Prostate. 1989; 15:23-40.

9. Ho SM. Estrogens and anti-estrogens: key mediators of prostate carcinogenesis and new therapeutic candidates. Journal of cellular biochemistry. 2004; 91:491-503.

10. Steiner MS and Raghow S. Antiestrogens and selective estrogen receptor modulators reduce prostate cancer risk. World journal of urology. 2003; 21:31-36.

11. Smith MR, Morton RA, Barnette KG, Sieber PR, Malkowicz SB, Rodriguez D, Hancock ML and Steiner MS.
Toremifene to reduce fracture risk in men receiving androgen deprivation therapy for prostate cancer. The Journal of urology. 2013; 189(1 Suppl):S45-50.

12. Smith MR, Fallon MA, Lee $H$ and Finkelstein JS. Raloxifene to prevent gonadotropin-releasing hormone agonist-induced bone loss in men with prostate cancer: a randomized controlled trial. The Journal of clinical endocrinology and metabolism. 2004; 89:3841-3846.

13. Saltzstein D, Sieber P, Morris T and Gallo J. Prevention and management of bicalutamide-induced gynecomastia and breast pain: randomized endocrinologic and clinical studies with tamoxifen and anastrozole. Prostate cancer and prostatic diseases. 2005; 8:75-83.

14. Kunath F, Keck B, Antes G, Wullich B and Meerpohl JJ. Tamoxifen for the management of breast events induced by non-steroidal antiandrogens in patients with prostate cancer: a systematic review. BMC medicine. 2012; 10:96.

15. Prins GS and Korach KS. The role of estrogens and estrogen receptors in normal prostate growth and disease. Steroids. 2008; 73:233-244.

16. Bossard C, Busson M, Vindrieux D, Gaudin F, Machelon V, Brigitte M, Jacquard C, Pillon A, Balaguer P, Balabanian $\mathrm{K}$ and Lazennec $\mathrm{G}$. Potential role of estrogen receptor beta as a tumor suppressor of epithelial ovarian cancer. PloS one. 2012; 7:e44787.

17. Slusarz A, Jackson GA, Day JK, Shenouda NS, Bogener JL, Browning JD, Fritsche KL, MacDonald RS, BeschWilliford CL and Lubahn DB. Aggressive prostate cancer is prevented in ERalphaKO mice and stimulated in ERbetaKO TRAMP mice. Endocrinology. 2012; 153:4160-4170.

18. Paruthiyil S, Parmar H, Kerekatte V, Cunha GR, Firestone GL and Leitman DC. Estrogen receptor beta inhibits human breast cancer cell proliferation and tumor formation by causing a G2 cell cycle arrest. Cancer research. 2004; 64:423-428.

19. Muthusamy S, Andersson S, Kim HJ, Butler R, Waage L, Bergerheim U and Gustafsson JA. Estrogen receptor beta and 17beta-hydroxysteroid dehydrogenase type 6 , a growth regulatory pathway that is lost in prostate cancer. Proceedings of the National Academy of Sciences of the United States of America. 2011; 108:20090-20094.

20. McPherson SJ, Hussain S, Balanathan P, Hedwards SL, Niranjan B, Grant M, Chandrasiri UP, Toivanen R, Wang Y, Taylor RA and Risbridger GP. Estrogen receptor-beta activated apoptosis in benign hyperplasia and cancer of the prostate is androgen independent and TNFalpha mediated. Proceedings of the National Academy of Sciences of the United States of America. 2010; 107:3123-3128.

21. Hussain S, Lawrence MG, Taylor RA, Lo CY, Frydenberg M, Ellem SJ, Furic L and Risbridger GP. Estrogen receptor beta activation impairs prostatic regeneration by inducing apoptosis in murine and human stem/progenitor enriched cell populations. PloS one. 2012; 7:e40732. 
22. Nakajima Y, Akaogi K, Suzuki T, Osakabe A, Yamaguchi C, Sunahara N, Ishida J, Kako K, Ogawa S, Fujimura T, Homma Y, Fukamizu A, Murayama A, Kimura K, Inoue S and Yanagisawa J. Estrogen regulates tumor growth through a nonclassical pathway that includes the transcription factors ERbeta and KLF5. Science signaling. 2011; 4:ra22.

23. Zellweger T, Sturm S, Rey S, Zlobec I, Gsponer JR, Rentsch CA, Terracciano LM, Bachmann A, Bubendorf L and Ruiz C. Estrogen receptor beta expression and androgen receptor phosphorylation correlate with a poor clinical outcome in hormone-naive prostate cancer and are elevated in castration-resistant disease. Endocrine-related cancer. 2013; 20:403-413.

24. Leav I, Lau KM, Adams JY, McNeal JE, Taplin ME, Wang J, Singh $\mathrm{H}$ and Ho SM. Comparative studies of the estrogen receptors beta and alpha and the androgen receptor in normal human prostate glands, dysplasia, and in primary and metastatic carcinoma. Am J Pathol. 2001; 159:79-92.

25. Dey P, Jonsson P, Hartman J, Williams C, Strom A and Gustafsson JA. Estrogen receptors beta1 and beta2 have opposing roles in regulating proliferation and bone metastasis genes in the prostate cancer cell line PC3. Molecular endocrinology. 2012; 26:1991-2003.

26. Ricke WA, McPherson SJ, Bianco JJ, Cunha GR, Wang $\mathrm{Y}$ and Risbridger GP. Prostatic hormonal carcinogenesis is mediated by in situ estrogen production and estrogen receptor alpha signaling. Faseb J. 2008; 22:1512-1520.

27. Bonkhoff H, Fixemer T, Hunsicker I and Remberger K. Estrogen receptor expression in prostate cancer and premalignant prostatic lesions. Am J Pathol. 1999; 155:641-647.

28. Mundy GR. Metastasis to bone: causes, consequences and therapeutic opportunities. Nature reviews Cancer. 2002; 2:584-593.

29. Wang S, Gao J, Lei Q, Rozengurt N, Pritchard C, Jiao J, Thomas GV, Li G, Roy-Burman P, Nelson PS, Liu X and $\mathrm{Wu}$ H. Prostate-specific deletion of the murine Pten tumor suppressor gene leads to metastatic prostate cancer. Cancer cell. 2003; 4:209-221.

30. Singh AS and Figg WD. In vivo models of prostate cancer metastasis to bone. The Journal of urology. 2005; 174:820-826.

31. Mishra S, Tang Y, Wang L, deGraffenried L, Yeh IT, Werner S, Troyer D, Copland JA and Sun LZ. Blockade of transforming growth factor-beta (TGFbeta) signaling inhibits osteoblastic tumorigenesis by a novel human prostate cancer cell line. Prostate. 2011; 71:1441-1454.

32. Tsai JH, Donaher JL, Murphy DA, Chau S and Yang J. Spatiotemporal regulation of epithelial-mesenchymal transition is essential for squamous cell carcinoma metastasis. Cancer cell. 2012; 22:725-736.

33. Mak P, Leav I, Pursell B, Bae D, Yang X, Taglienti CA, Gouvin LM, Sharma VM and Mercurio AM. ERbeta impedes prostate cancer EMT by destabilizing HIF-1alpha and inhibiting VEGF-mediated snail nuclear localization: implications for Gleason grading. Cancer cell. 2010; 17:319-332.

34. Windahl SH, Borjesson AE, Farman HH, Engdahl C, Moverare-Skrtic S, Sjogren K, Lagerquist MK, Kindblom JM, Koskela A, Tuukkanen J, Divieti Pajevic P, Feng JQ, Dahlman-Wright K, Antonson P, Gustafsson JA and Ohlsson C. Estrogen receptor-alpha in osteocytes is important for trabecular bone formation in male mice. Proceedings of the National Academy of Sciences of the United States of America. 2013; 110:2294-2299.

35. Khosla S, Oursler MJ and Monroe DG. Estrogen and the skeleton. Trends in endocrinology and metabolism. 2012; 23:576-581.

36. Rucci $\mathrm{N}$ and Teti A. Osteomimicry: how tumor cells try to deceive the bone. Frontiers in bioscience. 2010; 2:907-915.

37. Koeneman KS, Yeung F and Chung LW. Osteomimetic properties of prostate cancer cells: a hypothesis supporting the predilection of prostate cancer metastasis and growth in the bone environment. Prostate. 1999; 39:246-261.

38. Lin DL, Tarnowski CP, Zhang J, Dai J, Rohn E, Patel $\mathrm{AH}$, Morris MD and Keller ET. Bone metastatic LNCaPderivative $\mathrm{C} 4-2 \mathrm{~B}$ prostate cancer cell line mineralizes in vitro. Prostate. 2001; 47:212-221.

39. Zhau HE, He H, Wang CY, Zayzafoon M, Morrissey C, Vessella RL, Marshall FF, Chung LW and Wang R. Human prostate cancer harbors the stem cell properties of bone marrow mesenchymal stem cells. Clinical cancer research. 2011; 17:2159-2169.

40. Nelson JB, Hedican SP, George DJ, Reddi AH, Piantadosi $\mathrm{S}$, Eisenberger MA and Simons JW. Identification of endothelin-1 in the pathophysiology of metastatic adenocarcinoma of the prostate. Nature medicine. 1995; 1:944-949.

41. Dai J, Keller J, Zhang J, Lu Y, Yao Z and Keller ET. Bone morphogenetic protein- 6 promotes osteoblastic prostate cancer bone metastases through a dual mechanism. Cancer research. 2005; 65:8274-8285.

42. Dai J, Hall CL, Escara-Wilke J, Mizokami A, Keller JM and Keller ET. Prostate cancer induces bone metastasis through Wnt-induced bone morphogenetic protein-dependent and independent mechanisms. Cancer research. 2008; 68:5785-5794.

43. Virk MS, Petrigliano FA, Liu NQ, Chatziioannou AF, Stout D, Kang CO, Dougall WC and Lieberman JR. Influence of simultaneous targeting of the bone morphogenetic protein pathway and RANK/RANKL axis in osteolytic prostate cancer lesion in bone. Bone. 2009; 44:160-167.

44. Fradet A, Sorel H, Depalle B, Serre CM, Farlay D, Turtoi A, Bellahcene A, Follet H, Castronovo V, Clezardin P and Bonnelye E. A new murine model of osteoblastic/osteolytic lesions from human androgen-resistant prostate cancer. PloS one. 2013; 8:e75092.

45. Wu TT, Sikes RA, Cui Q, Thalmann GN, Kao C, Murphy CF, Yang $H$, Zhau HE, Balian $G$ and Chung LW. Establishing human prostate cancer cell xenografts in bone: 
induction of osteoblastic reaction by prostate-specific antigen-producing tumors in athymic and SCID/bg mice using LNCaP and lineage-derived metastatic sublines. International journal of cancer. 1998; 77:887-894.

46. Harkonen PL and Makela SI. Role of estrogens in development of prostate cancer. The Journal of steroid biochemistry and molecular biology. 2004; 92:297-305.

47. Zayzafoon M, Abdulkadir SA and McDonald JM. Notch signaling and ERK activation are important for the osteomimetic properties of prostate cancer bone metastatic cell lines. The Journal of biological chemistry. 2004; 279:3662-3670.

48. Tohfe M, Baki SA, Saliba W, Ghandour F, Ashou R, Ghazal G, Bahous J and Chamseddine N. Metastatic prostate adenocarcinoma presenting with pulmonary symptoms: a case report and review of the literature. Cases journal. 2008; 1:316.

49. Troyer DA, Tang Y, Bedolla R, Adhvaryu SG, Thompson IM, Abboud-Werner S, Sun LZ, Friedrichs WE and deGraffenried LA. Characterization of PacMetUT1, a recently isolated human prostate cancer cell line. Prostate. 2008; 68:883-892.
50. Mishra S, Lin CL, Huang TH, Bouamar H and Sun LZ. MicroRNA-21 inhibits p57Kip2 expression in prostate cancer. Molecular cancer. 2014; 13:212.

51. Guise TA, Yin JJ, Taylor SD, Kumagai Y, Dallas M, Boyce BF, Yoneda T and Mundy GR. Evidence for a causal role of parathyroid hormone-related protein in the pathogenesis of human breast cancer-mediated osteolysis. The Journal of clinical investigation. 1996; 98:1544-1549.

52. Mishra S, Deng JJ, Gowda PS, Rao MK, Lin CL, Chen CL, Huang T and Sun LZ. Androgen receptor and microRNA-21 axis downregulates transforming growth factor beta receptor II (TGFBR2) expression in prostate cancer. Oncogene. 2014; 33:4097-4106.

53. Li B and Dewey CN. RSEM: accurate transcript quantification from RNA-Seq data with or without a reference genome. BMC Bioinformatics. 2011; 12:323.

54. Mortazavi A, Williams BA, McCue K, Schaeffer L and Wold B. Mapping and quantifying mammalian transcriptomes by RNA-Seq. Nat Methods. 2008; 5:621-628. 